\title{
Cloning, expression and purification of resistance gene analogue RGPM 301 from pearl millet in Escherichia coli
}

\author{
Mariswamy Veena ${ }^{1}$, Prasad Melvin ${ }^{1}$, Sekhar Shailasree ${ }^{2 *}$, Kukkundoor Ramachandra Kini ${ }^{1}$ \\ ${ }^{1}$ Department of Studies in Biotechnology, Manasagangotri, University of Mysore, Mysore 570 006, Karnataka, India. \\ ${ }^{2}$ Institution of Excellence, Vijnana Bhavan, Manasagangotri, University of Mysore, Mysore 570 006, Karnataka, India.
}

\begin{tabular}{|c|c|}
\hline ARTICLE INFO & ABSTRACT \\
\hline Article history: & Plants combat their pathogens with an array of defense responses. One of the key mechanisms involves products \\
\hline Received on: 12/03/2016 & of resistance $(R)$ genes which are responsible for recognition of effector molecules from pathogens and \\
\hline Revised on: 26/03/2016 & subsequent triggering of defense responses. Resistance gene analogues (RGAs) containing the specific conserved \\
\hline Accepted on: 16/04/2016 & domains of $R$-genes are isolated from various plants using degenerate oligonucleotide primer based PCR \\
\hline Available online: $21 / 04 / 2016$ & $\begin{array}{l}\text { approach. In an earlier study, } R G P M 301 \text { an RGA from pearl millet shown to be involved in resistance } \\
\text { mechanism against downy mildew disease was isolated and characterized. In the present study, RGPM } 301\end{array}$ \\
\hline $\begin{array}{l}\text { Key words: } \\
\text { pRSET A, BL21 (DE3), } \\
\text { IPTG, CC-NBS-LRR, } \\
\text { Affinity purification. }\end{array}$ & $\begin{array}{l}\text { containing an open reading frame (ORF) of } 992 \text { amino acids was cloned into pRSET A expression vector and } \\
\text { expressed in Escherichia coli as a Hig-tag fusion protein. The recombinant RGA RGPM } 301 \text { was purified to near } \\
\text { homogeneity using the Nickel-CL agarose column. Its molecular mass was found to be } 120 \mathrm{kDa} \text { when separated } \\
\text { on the SDS-PAGE which was confirmed by western blotting analysis using the anti-His antibody. The purified } \\
\text { protein was subjected to in-gel trypsin digestion followed by mass spectrometric analysis for the confirmation of } \\
\text { its identity. These findings facilitate further studies on the exact role of this RGA in the pearl millet downy } \\
\text { mildew host pathogen system. }\end{array}$ \\
\hline
\end{tabular}

\section{INTRODUCTION}

Plants have developed effective and sophisticated mechanisms in pathogen perception and defense against their attack. The resistance $(R)$ genes of plants with specific conserved domains and motifs are known to play an important role in disease resistance. The $R$-gene products of the adaptive immune system recognizes the effector molecules from the pathogen and triggers the defense response with a localized host cell death or the hypersensitive response limiting the spread of the pathogen from the site of infection [1]. Based on the structural characteristics of the encoded R-proteins they are distinguished as nucleotide binding site-leucine rich repeats (NBS-LRR), receptor like serine-threonine kinases and extracellular/intracellular receptor like proteins [2]. Majority of the plant $R$-genes are members of NBS-LRR gene family conferring resistance to a wide range of pathogenic bacteria, fungi, viruses and pests such as insects and nematodes [3]. The NBS-LRR can be further categorized as toll/interleukin receptor

* Corresponding Author

E-mail address: shailasree@ioe.uni-mysore.ac.in Phone: 0091-821-2419478
TIR-NBS-LRR (TNL) or coiled coil-NBS-LRR (CNL/CC-NBSLRR) [4]. Most of the NBS-LRR and CNL encoding genes are found in monocots than in the dicots. Plant $R$-genes with such domains have been isolated by following methods such as positional cloning, transposon tagging and homologous cloning [5]. Since specific domains in $R$-genes are conserved across plant species, novel resistance gene analogues (RGAs) have been isolated from various plants using degenerate oligonucleotide primer based polymerase chain reaction (PCR) approach [6]. These, RGAs are useful tools for the isolation of full-length $R$ genes which provides vital information about the organization of these genes, their expression, roles in resistance mechanism and evolution [7]. Cloning of the $R$-genes and their heterologous expression in other host expression systems helps in establishing their functional characteristics. Protein isolation from plants is found to be a tedious process and may result in poor yields during purification. Hence, in vitro expression systems of bacteria, yeast, insect cells and Xenopus laevis oocytes which are available are used for overexpression of the encoded R-proteins with fusion tags. These methods produce large-scale plant proteins in suitable hosts and are helpful in validation of their biochemical and biophysical features [8]. 
Pearl millet [Pennisetum glaucum (L.) R. Br.] grown in the arid and semi-arid tropics of Indian subcontinent and Africa serves as a staple food and fodder crop of millions of poor families of these regions [9]. The crop is found to possess high potentiality with tolerance to high temperatures and also drought stress conditions [10]. The biotrophic oomycete Sclerospora graminicola (Sacc.) Schroet., causes the downy mildew disease in pearl millet leading to about $60 \%$ crop loss [11].

The resistance induced in the plants is often suppressed by pathogens. Such competitive evolution of the pathogen leads to break down of resistance. The pathogen causing downy mildew in pearl millet also evolves rapidly and results in the quick breakdown of resistance [12].

In an earlier study at our department, a set of 22 putative RGAs were identified in pearl millet using the conserved sequences of known $R$-genes by candidate gene approach method. Of the clones obtained, RGPM 301 (GenBank accession number: AY117410) which contained a partial sequence was $83 \%$ similar to rice R-proteins [13]. To identify and characterize the protein encoded by this partial sequence the full-length gene was isolated using rapid amplification of cDNA ends PCR approach [14]. This RGA, was 3552 bp long comprising an ORF of 2979 bp (GenBank accession number: KP226586) coding for 992 amino acids. Based on the conserved domains and motifs this CC-NBS-LRR gene was grouped as a non-TIR NBS LRR containing RGA [14]. Quantitative real time-polymerase chain reaction (qRT-PCR) studies revealed higher expression of transcripts of RGPM 301 in pearl millet cultivar resistant to downy mildew upon infection with the pathogen $S$. graminicola, as well as upon treatment with biotic and abiotic elicitors [14].

These studies indicate a role for this RGA in resistance mechanisms of pearl millet against downy mildew. In order to have a better understanding of the function of RGPM 301 in pearl millet downy mildew system, in the present study this full-length gene was cloned, expressed as a fusion protein in $E$. coli and purified.

\section{MATERIALS AND METHODS}

\subsection{Bacterial strain, vector and chemicals}

The bacterial strain E. coli BL21 (DE3) was used for expression of RGA RGPM 301. The vector pRSET A plasmid was obtained from Invitrogen, Bangalore and used in expression studies. The restriction enzymes BamHI and NcoI were procured from Merck Biosciences, Bangalore. The molecular biology reagents of the highest grade were purchased from commercial sources.

\subsection{Recombinant plasmid construction}

The ORF of $R$-gene RGA RGPM 301 which contained the CC-NBS-LRR region was previously amplified, cloned in $\mathrm{pTZ57R/T}$ vector and sequenced (GenBank Accession No. KP226586) [14]. Plasmid DNA was isolated using GeneJET ${ }^{\mathrm{TM}}$ plasmid miniprep kit (Fermentas). The primers PMRGPM-RE-F forward (5'-CGGGATCCATGGGCACCGTTTTGGAGTCTCTTGC TTGG-3') and PMRGPM-RE-R reverse (5'-CATGCCATGG CTAATGATAGAGAGATTCATCTGGAAATATATCTCG-3') bearing BamHI and NcoI restriction sites (underlined) respectively were designed based upon the complete sequence and used for PCR amplification of RGA RGPM 301. The PCR conditions included: initial denaturation at $94{ }^{0} \mathrm{C}$ for $5 \mathrm{~min}$ followed by 30 cycles of denaturation at $94{ }^{\circ} \mathrm{C}$ for $45 \mathrm{~s}$, annealing at $60{ }^{\circ} \mathrm{C}$ for 1 min and polymerization at $72{ }^{\circ} \mathrm{C}$ for $1 \mathrm{~min}$ with a final extension of $10 \mathrm{~min}$ at $72{ }^{\circ} \mathrm{C}$. Following amplification, the purified PCR product was digested with BamHI and NcoI and cloned into pRSET A vector to generate an expression construct. This recombinant vector containing the RGPM 301 fused to a His-tag was transformed into E. coli BL21 (DE3). Presence of the gene in the vector was analyzed by colony PCR and its reading frame was confirmed by DNA sequencing.

\subsection{Overexpression of recombinant RGA RGPM 301}

The BL21 (DE3) strain harboring the recombinant plasmid was grown overnight at $37{ }^{\circ} \mathrm{C}$ in the Leuria Bertani medium supplemented with ampicillin $(100 \mu \mathrm{g} / \mathrm{mL})$ with shaking at $250 \mathrm{rpm}$ until $\mathrm{A}_{600}$ was 0.8. The recombinant protein was induced by IPTG (isopropylthio- $\beta$-D-galactoside) with a final concentration of $1 \mathrm{mM}$ and grown for $6 \mathrm{~h}$ at $37{ }^{\circ} \mathrm{C}$ [15]. The cells were harvested at $8000 \mathrm{rpm}$ for $10 \mathrm{~min}$ at $4{ }^{\circ} \mathrm{C}$ and were lysed in $20 \mathrm{mM}$ phosphate buffer $\mathrm{pH} 7.4$ by sonication. The cell lysate was centrifuged at $20,000 \mathrm{~g}$ for $20 \mathrm{~min}$ at $4{ }^{\circ} \mathrm{C}$. The supernatant and the pellet were further evaluated.

\subsection{Affinity purification of RGA RGPM 301 expressed in BL21 (DE3)}

The Histidine-tagged recombinant RGA RGPM 301 protein was purified using His-Tag Fusion Protein Purification Kit (Merck Biosciences, Bangalore) according to the manufacturer's instructions. The Nickel-CL agarose column $(2.5 \times 10.0 \mathrm{~cm})$ was equilibrated with the equilibration buffer. The clarified lysate was loaded onto the column and the bound (His) ${ }_{6}$-tagged fusion protein was eluted. The eluted fractions were further analyzed for the recombinant protein by polyacrylamide gel electrophoresis.

\subsection{Protein analysis}

The protein was estimated and sodium dodecyl sulfatepolyacrylamide gel electrophoresis (SDS-PAGE) was performed according to Laemmli [16]. Fifty micrograms of bacterial soluble total protein and $10 \mu \mathrm{g}$ of purified protein were mixed with SDSPAGE loading dye followed by incubation at $90{ }^{\circ} \mathrm{C}$ for $10 \mathrm{~min}$ and loaded on a $10 \%$ SDS-PAGE gel. The gel was stained with Coomassie blue and assessed for protein expression.

\subsection{Western blot analysis}

Following SDS-PAGE, the separated protein was transferred electrophoretically on to a polyvinylidine difluoride (PVDF) membrane using Multiphor II apparatus (LKB, Pharmacia). The blot was incubated with $5 \%(\mathrm{w} / \mathrm{v})$ milk powder 
of blotting-grade in Tris-buffered saline (TBS: $10 \mathrm{mM}$ Tris $\mathrm{HCl}$ $\mathrm{pH} 8.0,150 \mathrm{mM} \mathrm{NaCl}$ ) and washed 3 times for $5 \mathrm{~min}$ each with TBST [TBS with $0.05 \%(w / v)$ Tween-20]. The blot was then incubated with Histidine-Tag Mouse Monoclonal Antibody at 37 ${ }^{0} \mathrm{C}$ for $90 \mathrm{~min}$ and washed 5 times with TBST. The secondary antibody anti-mouse conjugated to horseradish peroxidase (1:1000 dilution in blocking buffer) was added and incubated for $60 \mathrm{~min}$ at $37{ }^{0} \mathrm{C}$. Finally the blot was washed thrice with TBST and developed with horseradish peroxidase substrates 3, 3'-diaminobenzedine and hydrogen peroxide.

\subsection{In-gel trypsin digestion}

The in-gel digestion of the recombinant expressed protein separated by SDS-PAGE was processed as described by Ray et al. [17] with slight modifications. The gel piece was diced and destained in $100 \mu \mathrm{l}$ of destaining solution (50 $\mathrm{mM}$ ammonium bicarbonate/acetonitrile of $1: 1, \mathrm{v} / \mathrm{v}$ ) with intermittent gentle vortexing until most of the Coomassie dye was removed. The gel was dehydrated with $100 \%$ acetonitrile (ACN) and the shrunken pieces were incubated at $56{ }^{0} \mathrm{C}$ for $1 \mathrm{~h}$ in reducing solution $(10$ $\mathrm{mM}$ Dithiothreitol in $100 \mathrm{mM}$ ammonium bicarbonate) and washed in $100 \mu \mathrm{l}$ of $25 \mathrm{mM}$ ammonium bicarbonate. After reduction the gel pieces were incubated in alkylation solution (55 $\mathrm{mM}$ iodoacetamide in $100 \mathrm{mM}$ ammonium bicarbonate) in dark for $20 \mathrm{~min}$ at room temperature, washed with $25 \mathrm{mM}$ ammonium bicarbonate and dehydrated in $100 \%$ acetonitrile. The gel pieces were air-dried and incubated in $25 \mu \mathrm{l}$ of $12.5 \mathrm{ng} / \mu \mathrm{l}$ trypsin (Proteomics Grade, Sigma) at $37^{\circ} \mathrm{C}$ for $17 \mathrm{~h}$.

The supernatant containing the peptide mixtures were collected into a fresh microfuge tube. The remaining peptides in the gel pieces were extracted sequentially using $50 \mu \mathrm{l}$ each of extraction buffers 1 (60\% ACN with $0.1 \%$ formic acid) and 2 (100\% ACN) respectively. Supernatant was collected from both the peptide extraction steps and were pooled with earlier peptide fraction and dried in SpeedVac.
This was followed by reconstitution of peptides in $20 \mu \mathrm{l}$ of $0.1 \%$ formic acid and was desalted by custom made desalting tips using C-18 solid phase extraction disks (3M Empore) as described by Rappsilber et al. [18].

\subsection{Mass Spectrometric Analysis}

The peptide mixture which was desalted was subjected to fractionation by Agilent 6550 iFunnel QTOF mass spectrometer (Agilent Technologies) coupled to an Agilent 1260 Infinity Capillary Pump and 1260 Infinity Nanoflow Pump LC system (Agilent). The desalted peptide samples were loaded onto a ProteinID-Chip Zorbax 300SB-C18 $5 \mu \mathrm{m}$ via an Infinity Autosampler (Agilent Technologies). The data was acquired by the Agilent Mass Hunter Workstation Software, LC/MS Data Acquisition B.05.00 (Build 5.01.5125.1) operating in auto MS/MS mode. The data files were processed in Agilent Mass Hunter Spectrum Mill MS Proteomics Workbench software (Version B.04.00.127) and analyzed in MASCOT search engine.

\section{RESULTS AND DISCUSSION \\ 3.1 Recombinant protein expression}

Previously, the full-length $R G A$ RGPM 301 was isolated and cloned in pTZ57R/T vector. The PCR amplified gene with primer pairs appropriate for expression studies generated an amplicon of $\sim 2979$ bp (Fig 1).

The obtained amplicon and the expression vector pRSET A were subjected to restriction digestion with BamHI and NcoI and the recombinant plasmid construct was generated. The pictorial representation of the construct obtained by SnapGene Viewer tool version 3.0.3 is depicted in Fig 2.

The most widely used E. coli strain for protein overexpression is BL21 (DE3) which provides the highest yield of target protein [19]. Hence, the construct was transformed into $E$. coli BL21 (DE3) and was confirmed by colony PCR and found to be in-frame by sequencing (Fig 3).

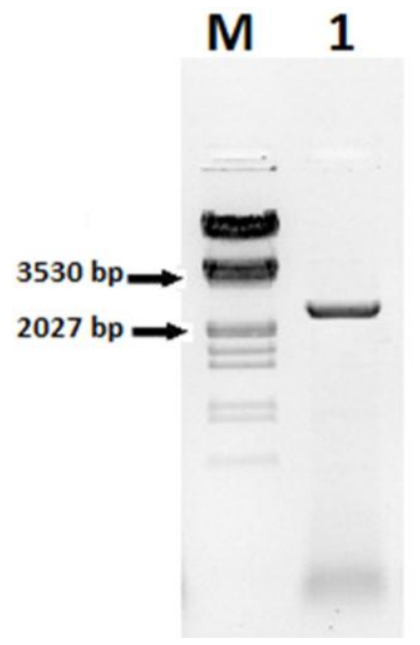

Fig. 1: Agarose gel electrophoresis of RGA RGPM 301. M-Lambda DNA/EcoRI+HindIII Marker (Thermo Scientific, Bangalore). Lane 1PMRGPM-RE-F/ PMRGPM-RE-R amplified PCR product of $\sim 2979 \mathrm{bp} .$. 

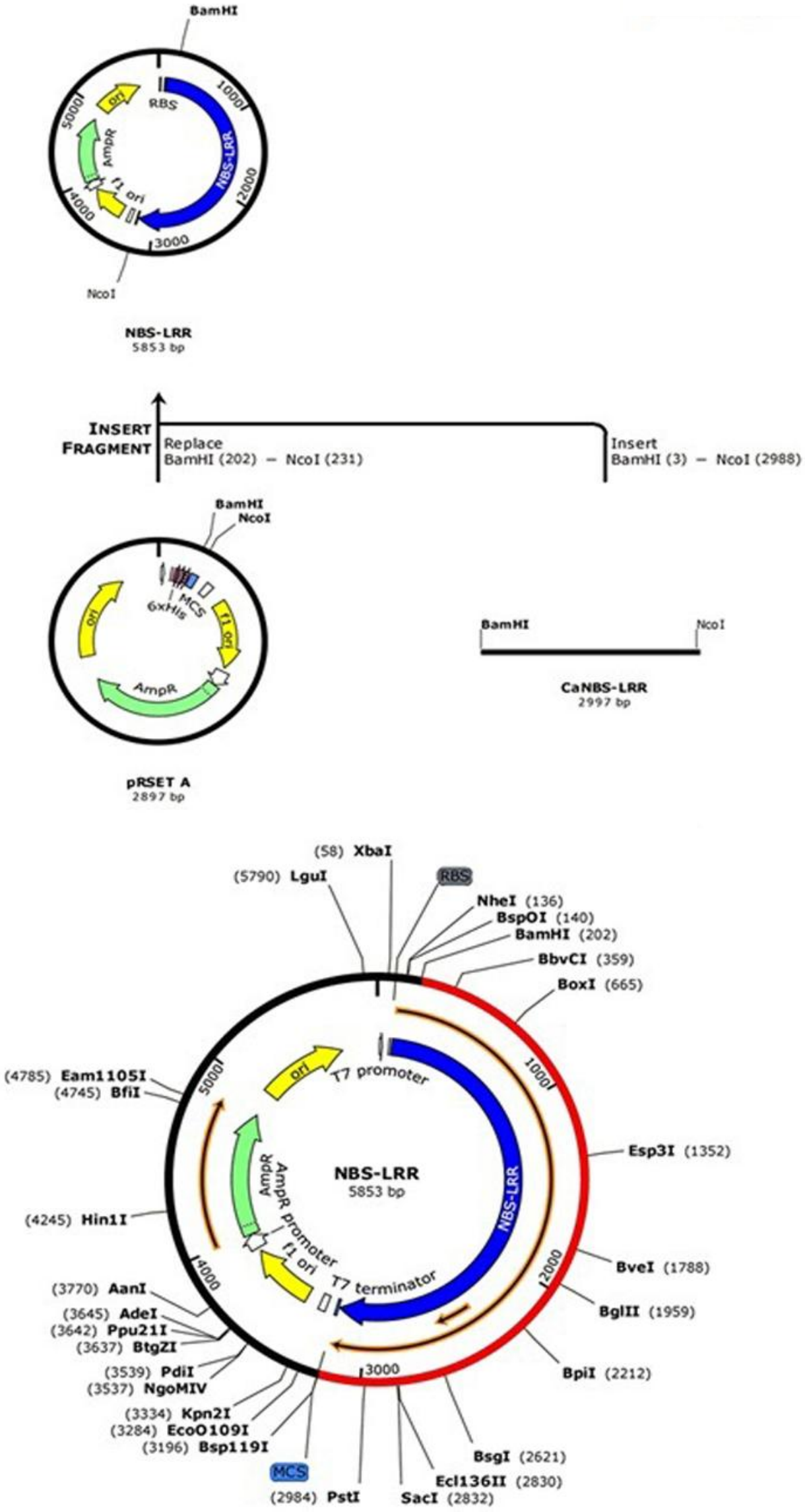

Fig. 2: Recombinant RGA RGPM 301 expression constructs. RGA RGPM 301 and expression vector pRSET A were restriction digested with BamHI and NcoI. These were ligated to form a recombinant RGA RGPM 301 expression construct. 


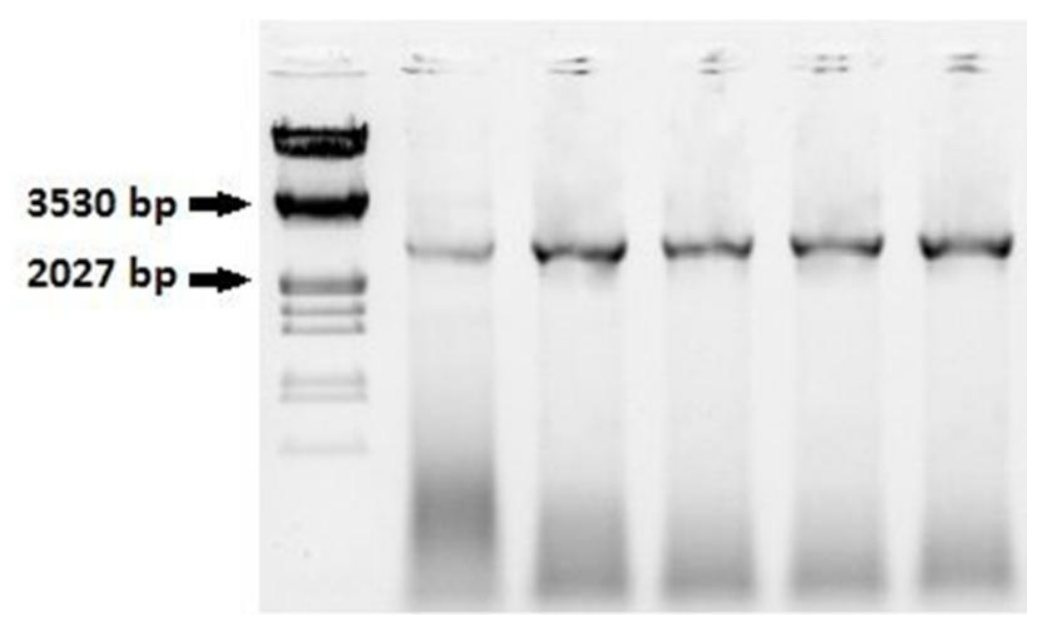

Fig. 3: Colony PCR confirmation of the RGA RGPM 301 amplified with expression primers.

\subsection{Induction of RGA RGPM 301}

IPTG $(1 \mathrm{mM})$ induction for $6 \mathrm{~h}$ induced the expression of recombinant protein. The recombinant RGA RGPM 301 was expressed with (His) $)_{6}$-tag derived from the pRSET A expression system. The fusion protein was mainly obtained in the soluble fraction of $E$. coli cell lysate with a molecular mass of approximately $120 \mathrm{kDa}$ resolved on a SDS-PAGE (Fig 4).

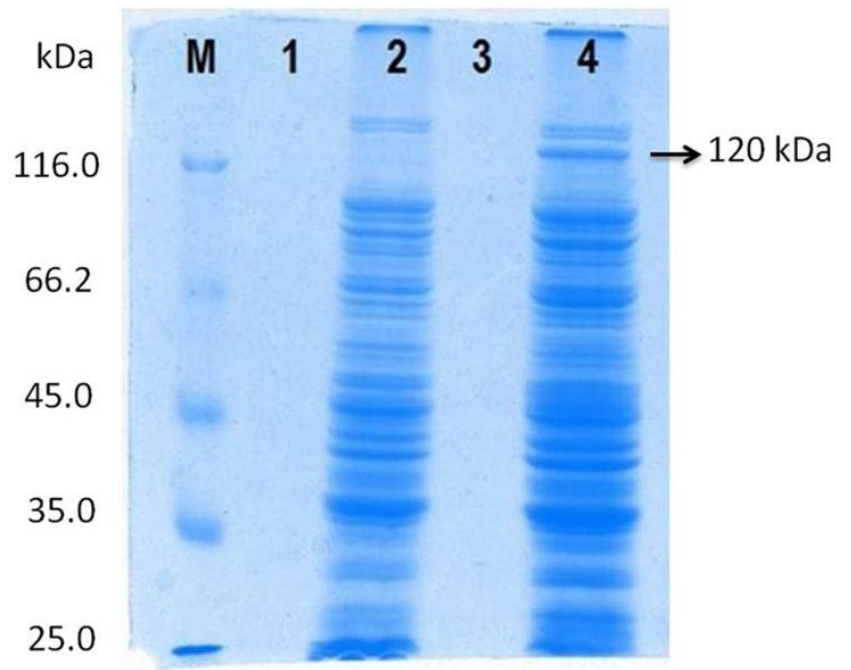

Fig. 4: Expression of recombinant RGA RGPM 301 in E. coli. Lane M: Molecular weight protein marker, Lane 1: uninduced pellet, Lane 2: induced pellet, Lane 3: uninduced supernatant, Lane 4: induced supernatant.

\subsection{Purification of His-tagged recombinant protein}

The recombinant RGA RGPM 301 was purified from the E. coli lysate using Nickel-CL agarose column chromatography. The non-specifically bound proteins of recombinant RGA RGPM 301 were washed with wash buffer and removed. The (His) $6^{-}$ tagged fusion protein bound to the agarose column was eluted and the fraction was analysed on SDS-PAGE for confirmation of the $120 \mathrm{kDa}$ recombinant protein to near homogeneity (Fig 5A). The molecular mass of the purified protein corresponded with the theoretically predicted molecular mass. Further, the identity of the (His) ${ }_{6}$-tagged protein was confirmed by probing the western blot with anti-His antibody (Fig 5B). In a similar study carried out by Ranjini et al. [20], the cDNA RGPM213 of pearl millet with NBSLRR region was expressed in pRSET-A and transformed in BL21 E. coli cells. The expressed His-tag recombinant protein of $35 \mathrm{kDa}$ was purified using nickel purification system.

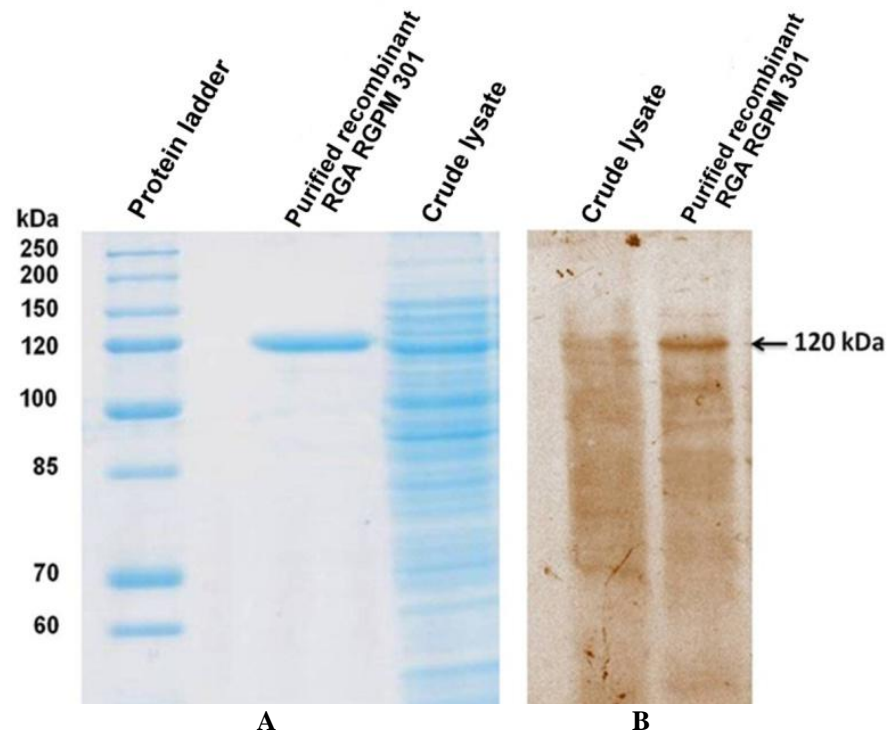

Fig. 5: Recombinant RGA RGPM 301 production and purification. (A) SDS PAGE profile of the recombinant protein $(1 \mu \mathrm{g})$ fraction purified by Nickel-CL agarose column and the soluble total protein $(50 \mu \mathrm{g})$ from E. coli strain BL21 (DE3) harvested $6 \mathrm{~h}$ post induction with $1 \mathrm{mM}$ IPTG. (B) Western blot showing the reaction of purified recombinant RGA RGPM 301 probed for the histidine-tag.

\subsection{MS/MS Analysis}

The recombinant expressed purified protein band of 120 $\mathrm{kDa}$ obtained after SDS-PAGE was excised, trypsin digested and subjected to LC/MS/MS analysis. The $120 \mathrm{kDa}$ protein after LC/MS/MS and MASCOT search showed several peptides with similarities to disease resistance proteins of different species. The 
peptide sequence RYFIIIEDLWASSMWDIVSR showed high similarity to Oryza sativa partial NBS-LRR resistance protein (Accession No. 383844187) and WLSLLLQHMK peptide sequence had a similarity with the Oryza sativa putative NB-ARC domain-containing protein (Accession No. 146394070). LVTNQLTSIAR peptide was similar to Zea mays putative leucine-rich repeat transmembrane protein kinase family protein (Accession No. 413945125). The peptide sequence VLADVSLISVSSNGEIVMHSLQRQMGK was found to be similar to Arabidopsis thaliana disease resistance protein SLH1 (Accession No. 51555866). Two of the peptide sequences VQVLPKSLGK and LASPDFVDLILGK were similar to Glycine max disease resistance protein RPM1-like (Accession No. 356515314) and NB-LRR type disease resistance protein Rps1-k1(Accession No.62632823) respectively. These results confirm the identity of the recombinant RGPM 301 as a RGA.

Isolation, expression and characterization of full-length $R$-genes is essential for gaining better understanding of the functions of proteins encoded by these genes in plants. Several studies have reported this approach. Two tomato $\mathrm{R}$ proteins, I-2 which conferred resistance to Fusarium oxysporum and Mi-1 conferring resistance to root-knot nematodes and potato aphids were purified as glutathione $S$-transferase fusions in $E$. coli expression system [21]. Similarly, a rice R1-NB a 809 amino acid orphan R-protein with $\mathrm{N}$-terminal extension containing a CC domain was expressed as a soluble recombinant protein in E. coli. and co-purified with a single contaminating protein by affinity purification [22]. Also, DNA fragments which encoded the ORF of the Pi-ta isolated from pCB1906, LRD and LRDA918S isolated and purified from the two-hybrid bait vector were cloned into pET29a and expressed in BL21 (DE3) for expression of the fusion proteins [23]. In the soybean R-protein RHG1-LRR, the LRR domain believed to recognize the elicitor was expressed, purified and refolded from E. coli [24]. A rust R-protein (M) of flax expressed in Pichia pastoris as a cytosolic protein was obtained in the soluble fraction which was purified to near homogeneity using ion exchange, metal affinity and size exclusion chromatography [25].

\section{CONCLUSIONS}

In this study, we report the successful heterologous expression of the recombinant fusion protein RGA RGPM 301 in E. coli. The full-length RGA RGPM 301 with 2979 bp encoding 992 amino acids was amplified by PCR and cloned into the expression vector pRSET A. The obtained recombinant plasmid construct was transformed into BL21 (DE3) cells and overexpressed with IPTG induction at $6 \mathrm{~h}$. The (His) 6 -tagged recombinant protein was obtained in the soluble fraction and purified using the Nickel-CL agarose column. The purified fusion protein of approximately $120 \mathrm{kDa}$ was confirmed by western blotting with mouse anti-His antibody. Finally, the purified protein was subjected to in-gel trypsin digestion and mass spectrometric analysis. The purified RGPM 301 can be used further for structural and functional characterization of this protein. Antibodies can be raised against this protein which will be helpful for isolation of the corresponding R-protein from pearl millet extracts and its localization in plant tissue. Such a study would pave a way for understanding the biochemical and molecular events that occur during the host pathogen interactions. These events will also contribute to understanding the role of $R$-genes in the plant disease resistance mechanism.

\section{ACKNOWLEDGEMENTS}

The first author is grateful to the University Grants Commission, New Delhi for providing financial assistance in the form of Rajiv Gandhi National Fellowship to carry out the research work in the Department of Studies in Biotechnology, University of Mysore, Mysore. We acknowledge the Institution of Excellence, University of Mysore, Mysore recognized by the Government of India with financial support from the Ministry of Human Resource Development.

We are thankful to Dr. Mayuri Nalin Gandhi and Ms. Manali Jadhav from HR-LCMS Lab, Sophisticated Analytical Instrumentation Facility, Indian Institute of Technology, Bombay, India for assisting us in LC/MS/MS analysis.

\section{REFERENCES}

1. Holt BF, Hubert DA, Dangl JL. Resistance gene signaling in plantscomplex similarities to animal innate immunity. Current Opinion in Immunology. 2003; 15: 20-25.

2. Sekhwal MK, Li P, Lam I, Wang X, Cloutier S, You FM. Disease resistance gene analogs (RGAs) in plants. International Journal of Molecular Sciences. 2015; 16: 19248-19290.

3. Dangl L, Jones J. Plant pathogens and integrated defense responses to infection. Nature. 2001; 411: 826-833.

4. Hammond-Kosack KE, Jones JD. Plant disease resistance genes. Annual review of plant physiology and plant molecular biology. 1997; 48: 575-607.

5. Hulbert SH, Webb CA, Smith SM, Sun Q. Resistance gene complexes: Evolution and utilization. Annual Review of Phytopathology. 2001; 39: 285-312.

6. Sharma TR, Das A, Kumar SP, Lodha ML. Resistance gene analogues as a tool for rapid identification and cloning of disease resistance genes in plants-a review. Journal of Plant Biochemistry and Biotechnology. 2009; 18:1-11.

7. He L, Du C, Covaleda L, Xu Z, Robinson AF, Yu JZ, Kohel RJ, Zhang HB. Cloning, characterization, and evolution of the NBS-LRR encoding resistance gene analogue family in polyploid cotton (Gossypium hirsutum L.). Molecular Plant-Microbe Interactions. 2004; 17: 1234-1241.

8. Yesilirmak F, Sayers Z. Heterologous expression of plant genes. International Journal of Plant Genomics. 2009 May 24; doi:10.1155/2009/296482.

9. Yadav OP, Rai KN. Genetic improvement of pearl millet in India. Agricultural Research. 2013; 2: 275-292.

10. Upadhyaya HD, Reddy KN, Gowda CLL. Pearl millet germplasm at ICRISAT genebank -status and impact. SAT eJournal. 2007; 3: 1-5. doi: $10.1017 / \mathrm{s} 1479262110000365$.

11. Thakur RP, Rao VP, Sharma R. Influence of dosage, storage time and temperature on efficacy of metalaxyl-treated seed for the control of pearl millet downy mildew. European Journal of Plant Pathology. 2011; 129: 353-359.

12. Lin WC, Lu CF, Wu JW, Cheng ML, Lin YM, Yang NS, Black L, Green SK, Wang FJ, Cheng PC. Transgenic tomato plants expressing 
the Arabidopsis NPR1 gene display enhanced resistance to a spectrum of fungal and bacterial diseases. Transgenic research. 2004; 13: 567 581.

13. Ramachandra SB, Sathyanarayana NR, Subramonium S, Shetty SH. Isolation, cloning and characterization of Resistance Gene Analogues in Pearl Millet based on conserved nucleotide binding sites. Journal of Phytopathology. 2011; 159: 382-389.

14. Veena M, Melvin P, Prabhu SA, Shailasree S, Shetty SH, Kini KR. Molecular cloning of a coiled-coil-nucleotide-binding-site-leucine-rich repeat gene from pearl millet and its expression pattern in response to the downy mildew pathogen. Molecular Biology Reports. 2016; 43: 117-128.

15. Sambrook J, Fritsch EF, Maniatis T. In: Nolan C (ed) Molecular cloning: a laboratory manual. Cold Spring Harbor Laboratory, Cold Spring Harbor.1989

16. Laemmli UK. Cleavage of structural proteins during the assembly of the head of bacteriophage T4. Nature. 1970; 227: 680-685.

17. Ray S, Kamath KS, Srivastava R, Raghu D, Gollapalli K, Jain R, Gupta SV, Ray S, Taur S, Dhali S. Serum proteome analysis of vivax malaria: An insight into the disease pathogenesis and host immune response. Journal of proteomics. 2012. 75; 3063-3080.

18. Rappsilber J, Ishihama Y, Mann M. Stop and go extraction tips for matrix-assisted laser desorption/ionization, nanoelectrospray and LC/MS sample pretreatment in proteomics. Analytical Chemistry. 2003; 75: 663-670.

19. Bolanos-Garcia VM, Davies OR. Structural analysis and classification of native proteins from $E$. coli commonly co-purified by immobilised metal affinity chromatography. Biochimica et Biophysica Acta. 2006; 1760: 1304-1313.

20. Ranjini P, Shailasree S, Kini KR, Shetty HS. Isolation and characterisation of a NBS-LRR resistance gene analogue from pearl millet. Archives of Phytopathology and Plant Protection. 2011; 44: 1014-1024.
21. Tameling WI, Elzinga SD, Darmin PS, Vossen JH, Takken FL, Haring MA, Cornelissen BJ. The tomato $R$ gene products I-2 and MI-1 are functional ATP-binding proteins with ATPase activity. Plant Cell. 2002; 14: 2929-2939.

22. Fenyk S, Campillo Ade S, Pohl E., Hussey PJ, Cann MJ. A nucleotide phosphatase activity in the nucleotide binding domain of an orphan resistance protein from rice. The Journal of Biological Chemistry. 2012; 287: 4023-4032.

23. Jia Y, McAdams SA, Bryan GT, Hershey HP, Valent B. Direct interaction of resistance gene and avirulence gene products confers rice blast resistance. The EMBO Journal. 2000; 19: 4004-4014.

24. Afzal AJ, Lightfoot DA. Soybean disease resistance protein RHG1LRR domain expressed, purified and refolded from Escherichia coli inclusion bodies: preparation for a functional analysis. Protein Expression and Purification. 2007; 53: 346-355.

25. Schmidt SA, Williams SJ, Wang CIA, Sornaraj P, James B, Kobe B, Dodds PN, Ellis JG, Anderson PA. Purification of the M flax-rust resistance protein expressed in Pichia pastoris. The Plant Journal. 2007; 50: 1107-1117.

\section{How to cite this article:}

Veena M., Melvin P, Shailasree S., Kini KR. Cloning, expression and purification of resistance gene analogue RGPM 301 from pearl millet in Escherichia coli. J App Biol Biotech, 2016; 4 (02): 053-059. DOI: 10.7324/JABB.2016.40208 